\title{
Blurring the Line Between For-Credit Curricular ANd NOT-For-CREDIT EXTRACURRICULAR ENINGEERING LEARNING ENVIRONMENTS
}

\author{
Sal Alajek, Alan Ham, Heather Murdock, Jonathan Verrett \\ Engineers Without Borders Canada Global Engineering Team \\ salajek@ewb.ca, alanham@ewb.ca, heathermurdock@ewb.ca, jonathan.verrett@mail.mcgill.ca
}

\begin{abstract}
Engineering student experience is highly influenced by the interplay between curricular and extracurricular learning environments on campus. Bridging between the two spaces, Engineers Without Borders (EWB) Canada builds on curricular content with extracurricular opportunities which not only reinforce leadership and communications skills, but also focus on complexity and systems thinking, globalization trends, and foundational attitudes of service to society. In recent years, EWB has been working collaboratively with specific engineering faculties in an attempt to bring these attributes to the classroom. This paper examines the efficacy of these opportunities, which blur the line between for-credit engineering curricular interactions and not-for-credit extracurricular engineering focused activities. Drawing on examples from institutions that have implemented credit for extracurricular activities and building on the 2013 Global Engineering Symposium's engineering education focused discussions at the Engineers Without Borders Canada annual national conference in Calgary, Alberta, we highlight the potential for the concept from the perspective of the student and the faculty.
\end{abstract}

Keywords: global engineering, service learning, Engineers Without Borders, extra-curricular, cocurricular, meta-cognition, leadership development

\section{INTRODUCTION}

The new Canadian Engineering Accreditation Board (CEAB) outcomes-based accreditation model outlines attributes that Canadian engineering graduates should possess in order to be effective professionals in an increasingly complex world [2]. Current teaching structures are being reevaluated to examine their effectiveness in developing these graduate attributes, and whether this innovative accreditation method necessitates further innovations in curriculum design [15]. Often in an undergraduate's academic career, a very rich extracurricular experience runs parallel, providing another education of sorts, with unique opportunities and relationships that cannot be obtained simply by going to class.

The suggestion exists that credit should be given for extracurricular activities, such as participation on engineering design teams, internships or volunteering with humanitarian engineering type organizations [15, 16]. EWB Canada's Global Engineering team has been facilitating discussion around engineering education for 10 years. Key to the success of the team has been collaboration with engineering faculties across Canada, which strive to keep their programs unique and contemporary, as well as with student chapter members, who continue to ask the tough questions about the effectiveness and relevance of their education in a metacognitive manner. This paper will examine a few specific programs with which EWB has been involved or studied, from both the educator and the student sides of the classroom.

\section{BACKGROUND}

Since its founding Engineers Without Borders members have desired to contribute to a larger discussion on the engineer's role in society. As part of this desire, EWB sought to define the Global Engineer and outline the key characteristics for engineers to succeed in the 21 st century [7]. These characteristics came from discussions with EWB members, university faculty, and industry leaders, with many of the characteristics overlapping with the CEAB graduate attributes [7]. EWB members have since continued to engage with students and faculty in discussions and actions to analyze and improve engineering education. These actions include the Global Engineering Symposia at our national conference, which have brought together academics and professional associations; designing courses and course components with various universities; and educating our members and other students about engineering curriculum design.

\section{NEW LEARNING PARADIGMS}


The idea of extracurricular activity complementing a post-secondary education is well-known. How these activities are perceived in contrast to formal academia varies. For many students and professors, extracurriculars are effective at developing "soft-skills" and may provide hands-on learning that is absent in university programs, however participation is a matter of the student's interest and availability. For others, extracurriculars are an essential part of the university experience, so much so that the term "extracurricular" is considered a misnomer. The term "co-curricular" is gaining usage, as way to elevate the idea of out-of-classroom activity [12]. Universities are now adding these experiences to transcripts to encourage students to get involved $[9,10]$. In the outcomes-based accreditation era, engineering faculties are discovering value in out-of-classroom learning, and Canada-wide organizations such as EWB can be a partner in developing content for attribute development [2].

EWB has designed, implemented and scaled extracurricular attribute developing activities in curricula across Canadian institutions. The 'Engineering First-Year "Root Causes Analysis", workshop is offered by EWB chapters in many first-year design courses. The original workshop was developed by EWB volunteers on international placements to share their learning about the complexity of engineering interventions in underdeveloped communities [6]. This system mapping workshop was then used by EWB student volunteer chapters as an extracurricular activity focused on discussing the role of engineering in the fight against poverty.

Following a few course instructors' requests for the workshop be run in their classrooms, the student groups revamped the workshop and offered it as curricular supplement for first-year engineering design classes across Canada. Multiple engineering universities now offer the workshop as part of their curriculum to every single first-year engineering student (most notably University of Toronto, McMaster University and Queen's University). What worked as an extracurricular activity for a small group of self-selected students was successfully scaled for all their cohort for-credit.

While engineering extracurricular activities offer many opportunities for student learning and growth, they can also serve as a testing ground for new curricular innovations. The development of initiatives such as the Engineering Centre for Experiential Learning (ExCEL) at McMaster University shows an increasing emphasis on providing space for extracurricular activities [10]. The centre will have student study spaces, computer labs and host design teams. It will be managed by engineering students, who will be active in deciding how the space will continue to be used. The project aims to create a hub for engineering student activity on campus while also providing valuable experiential learning and design opportunities.

Devoted extracurricular spaces such as the ExCEL can serve two functions for curricular development: on one hand engineering faculty can test new curriculum with interested subsets of students (A push model); and on the other hand curricular innovations can emerge organically through student activities and engaged faculty can select for successful innovations to be scaled in curriculum (A pull model). One example of the pull model is the system mapping workshop developed by EWB student chapters. These extracurricular spaces act as testing grounds for creating new curricular content.

\section{LEADERSHIP DEVELOPMENT}

Developing leadership skills is potentially one of the most critical opportunities engineering students gain in extracurricular environments. Students are able to learn by doing, and in out-of-classroom environments, they are placed in situations where they may need to organize a conference, launch a multiyear fundraising initiative, or lead a group of their peers towards a common goal. These students often take on those challenges with little to no previous management/leadership experience.

Service-learning, a "teaching and learning strategy that integrates meaningful community service with instruction and reflection to enrich the learning experience, teach civic responsibility, and strengthen communities" [14], is a successful bridging of the benefits of this extracurricular space and for-credit curriculum. Engineering students are incentivised to participate in initiatives which will develop their leadership skills with minimal constraints. Service learning encourages students to learn about subjects outside of their experience through simulation or direct engagement. Successful examples of bridging engineering service learning to be for-credit can be found in Queen's University's 4th year Mechanical Engineering elective course where students were challenged to "act as change agents" by implementing unsolicited energy conservation measures to improve the environmental performance [1].

Like any culture, engineering culture's development was influenced by its history. Engineering's 20th century history is rooted in military operations and accordingly the "engineering mindsets" can be structured and rigid [9]. World War I, World War II, and the Cold War (directly and indirectly) led to " $50 \%$ employment of engineers by the government" [9]. While it is important to maintain due diligence and sound technical practices at the centre of the profession, a mindset which encourages innovation and is open to questioning assumptions is critical to evolving the aforementioned engineering rigid mindset and allowing engineers to contribute to "sustainable community development" [9]. 
To move engineering away from a rigid mindset, EWB Chapters often supplement course content focused on engineering management with activities focused on emotional intelligence based learning. This learning may include:

- $\quad$ Building empathy

- Discussing fundamental power relationships between (Oppressed and Oppressor, gender issues, and the limits of the technocrat)

- Learning about different personality/learning types

- Taking the time to discuss how engineering teams feel, in addition to how well they perform

- Discussing team dynamics or health in addition to team performance

\section{ENGAGING UNDERGRADUATE STUDENTS IN ENGINEERING EDUCATION}

Through EWB's work in scaling the learning
environment innovations which emerged in extracurricular spaces, we encountered undergraduates having difficulty conducting meaningful discussions and struggling to improve their engineering curriculum and its delivery. A report by the American Society for Engineering Education lists a few key issues such as faculty awareness and resource availability [8]. In addition, the typical 4-year program is not conducive to understanding the effectiveness of content relevance, nor content delivery. Generally once students understand the design of their courses and programs, any recommendations to improve these programs can only be implemented following the students' graduation, thus discouraging feedback. In contrast, extracurricular activities provide students with outcomes that are directly affected by their involvement and they quickly experience the results of their ideas and actions. Unfortunately, extracurricular clubs can change rapidly and may be a completely different organization from one year to the next, making it difficult for clubs and faculties to have lasting relationships focused on meaningful curriculum change.

Metacognition, or analyzing how one thinks or studies, is an extremely useful skill for engineers in their professional career. Providing opportunities for students to analyze course material and curriculum design has been shown to motivate and engage students inside the classroom [4]. Students who were asked to use metacognition to analyze their learning in a given class were more motivated and able to set meaningful goals for their own learning [13]. Applying this same concept to engineering education, EWB has developed self pace learning modules to help students understand the theory behind engineering curricular design. The learning modules are framed to help interested students understand how engineering education "works" and more importantly how they can play an active role in influencing its evolution. The series of modules were introduced as part of EWB's Global Engineering program which is focused on supporting engineering education innovations. The modules stress big picture thinking and aims to expand engineering mindsets beyond technical constraints. The modules, dubbed "Global Engineering Ninja Training" attract a variety of engineering students interested in understanding and taking ownership of their education.

EWB's Global Engineering Ninja Training modules not only focus on giving students theoretical background on the structure of Canadian engineering education but also shape virtual peer-to-peer learning communities. EWB's network of 32 university chapters allow for students to interact, share, and create new initiatives by engaging with peers beyond their campus. This sharing accelerates student involvement in curriculum development and dissemination of engineering education practices. We found that as engineering students understand more about their education system, they are better able to take ownership, give feedback, and launch new extracurricular learning innovations.

Faculty are a key partner in providing spaces for student learning on curriculum. Throughout EWB's network faculties have provided a variety of ways for undergraduates to get involved in education such as: providing workshops during class time [6], support for panels and conferences on education [9], engagement in educational design committees [7] and assistance in designing and implementing courses [5]. By continuing to provide this support faculty will continue to engage students with a deep interest in educational design. We believe these deeply engaged student are extremely important to facilitate discussion and feedback from undergraduate students on curriculum design.

\section{CONCLUSION}

Extra-curricular activities provide a unique opportunity to improve leadership and project management skills, as well as to encourage to students to learn about and get deeply involved in subjects outside those they study formally. With outcome-based accreditation, faculties can tap into out-of-classroom activities to further develop contemporary curricula. Through Engineers Without Borders, student members have had success in scaling workshops into sessions that are not only run nationwide, but also appear within forcredit course syllabi. The deliberate creation of extracurricular spaces is being increasingly recognized as important for attribute development such as leadership, communication, ethics and community service. These environments can and have been used to test or create 
new curricular content by providing a place for students and faculty to discuss and engage with each other.

Leadership development can also be fostered through service learning, which encourages students to learn about subjects outside of their experience through simulation or direct engagement. Service learning is relatively new in the history of engineering education, however Queen's University has run a successful example of using forcredit service learning. EWB chapters often supplement such course content by providing a space for developing emotional intelligence skills.

Undergraduates are a key stakeholder in curriculum design and reform and their engagement is necessary for successful implementation of educational innovations. By providing information and a space for students to analyze curriculum across many Canadian institutions EWB is meaningfully engaging students and faculty in a discussion on engineering education. EWB's Curriculum Enhancement team will be continuing to facilitate and grow the space for engineering students to contribute to educational reform and design in the future.

\section{Acknowledgements}

The authors would like to extend their sincerest thanks to all of the attendees at the Global Engineering Symposium during the EWB National Conference 2013 in Calgary. The presentations and discussions at the event were part of the inspiration for this paper. The rest of the inspiration came from the wonderful people at Engineers Without Borders Canada, from the National Office to the Chapters both Student and Professional.

\section{References}

[1] K. Branker, J. Corbett, J. Webster and J. M. Pearce, "Hybrid Virtual- and Field Work-based Service Learning with Green Information Technology and Systems Projects," International Journal for Service Learning in Engineering, vol. 5, no. 2, pp 44-59, 2010

[2] Canadian Engineering Accreditation Board, Accreditation criteria and procedures 2010. Ottawa, ON: Engineers Canada, 2010, 83 pp. \{ISSN 1708-8054\}

Available as of June 30, 2010 from

http://www.engineerscanada.ca/e/files/Accreditation_Criteria _Procedures_2010.pdf

[3] Guy M. Cloutier, Pierre Savard, and Yves Boudreault, "Towards a scale and tool for the appraisal of CEAB attributes Progress report on a field test," in Proc. CEEA Canadian Engineering Education Conf., CEEC11, Andy Fisher (ed.) (St. John's, NL; 6-8 June 2011), 7 pp., 2011.
[4] Lyn Corno and Ellen B. Mandinach, "The role of cognitive engagement in classroom learning and motivation," Educational Psychologist, vol. 18, issue 2, pp 88-108, 1983

[5] Deborah Dysart-Gale and Govind Gopakumar, Contemporary Studies and Global Engineering: A Synergy. Toronto, ON: Engineers Without Borders Canada (EWB), 2013, Available as February 6, 2013 from http://my.ewb.ca/site_media/static/library/files/851/deborahdysart-gale-and-govind-gopakumar-concordia-universitycomplementary-studies-and-global-engineering-a-synergy.pdf

[6] Engineers Without Borders Canada, Root Causes of Poverty Workshop. Toronto, ON: Engineers Without Borders Canada, 2012, Available as of July 19, 2012 from http://my.ewb.ca/library/view/368/

[7] Jonathan M. Fishbein "The Global Engineer: An Implementation of Outcomes-based Accreditation Requirements," in Proc. of CDEN/C2E2 Conf., (Hamilton, ON; 27-29 July 2009), 6 pp., 2009.

[8] Leah H. Jamieson and Jack R. Lohmann, Innovation with Impact: Creating a Culture for Scholarly and Systematic Innovation in Engineering Education. Washington, DC: American Society for Engineering Education (ASEE), 2012, 77 pp. $\{$ ISBN-0-878-23240-0\}

Available as of June 1, 2012 from

http://www.asee.org/about-us/the-organization/advisorycommittees/Innovation-with-Impact

[9] Juan Lucena, How Might Engineers Achieve Systemic Change in Community Development? Bridging Sustainable Development and Social Justice. Toronto, ON: Engineers Without Borders Canada (EWB), 2013, Available as of February 6, 2013 from

http://my.ewb.ca/site_media/static/library/files/850/juan-lucenabridging-sustainable-community-development-and-socialjustice.pdf

[10] McMaster University, Engineering Centre for Experiential Learning (ExCEL). Hamilton, ON: McMaster University, 2013, Available as of January 24, 2013 from http://www.eng.mcmaster.ca/excel/

[11] Donald Presant, "ePortfolios to Build, Demonstrate and Maintain Professional Competence," in Proc. 2012 CEEA Canadian Engineering Education Conf., CEEC12, Withold Kinsner (ed.) (Winnipeg, MB; 17-20 June 2012), 2 pp., 2012.

[12] Egle Procuta, It's an extracurricular wonderland at Candian universities. Toronto, ON: The Globe and Mail, 2011, Available as of October 25, 2011 from http://www.theglobeandmail.com/news/national/education/its-

CEEA13; Paper 001 
an-extracurricular-wonderland-at-canadianuniversities/article601011/

[13] Dale H. Schunk and Barry J. Zimmerman, Motivation and self-regulated learning: Theory, research and applications. Mahwah, NJ: Erlbaum, 2007, 432 pp. \{ISBN: 978-0805-858983 \}

[14] Sarena D. Seifer and Kara Conners, Community Campus Partnerships for Health. Faculty Toolkit for ServiceLearning in Higher Education. Scotts Valley, CA: National Service-Learning Clearinghouse, 2007, 167 pp. Available as of May 1, 2013 from

http://www.servicelearning.org/library/resource/7120

[15] David Strong and Sue F. Young, "Consideration of the Design Attribute in the 2008 CEAB Accreditation Procedures," in Proc. of the 1st CEEA Conf., (Kingston, ON; 7-9 June 2010), 5 pp., 2010.

[16] University of Calgary, Leadership and Student Engagement: Co-Curricular Record. Calgary, AB: University of Calgary, 2013, Available as of May 1, 2013 from https://leadership.ucalgary.ca/about/pageOne.htm

[17] University of Ontario Institute of Technology, Getting Involved. Toronto, ON: University of Ontario Institute of Technology, 2013, Available as of May 1, 2013 from https:/uoit.ca/main/current-students/campus_life/gettinginvolved.php

CEEA13; Paper 001

Montreal, QC; June 17-20, $2013 \quad-5$ of 5 - 